\title{
1 Microaggregate stability and storage of organic carbon is affected by clay \\ 2 content in arable Luvisols
}

3 Lars Krause $^{\mathrm{a}^{*}}$, Andrei Rodionov ${ }^{\mathrm{b}}$, Steffen A. Schweizer ${ }^{\mathrm{c}}$, Nina Siebers ${ }^{\mathrm{a}}$, Eva

4 Lehndorff ${ }^{b}$, Erwin Klumpp ${ }^{a}$, Wulf Amelung ${ }^{a, b}$

5 a Forschungszentrum Jülich GmbH, Agrosphere (IBG-3) Institute of Bio- and Geosciences, Wilhelm

6 Johnen Straße, 52425 Jülich, Germany

$7 \quad{ }^{b}$ University of Bonn, Institute of Crop Science and Resource Conservation - Soil Science and Soil

8 Ecology, Nussallee 13, D-53115 Bonn, Germany

$9{ }^{\mathrm{c}}$ Technical University of Munich, Department Ecology and Ecosystem Management, Chair of Soil

10 Science, Emil-Ramann-Straße 2, D-85354 Freising-Weihenstephan, Germany

11 *Corresponding author, e-mail: I.krause@fz-juelich.de

13 Keywords: free, occluded, particle size distribution

\section{Abstract}

As soil microaggregates $(<250 \mu \mathrm{m}, \mathrm{SMA})$ usually withstand long-term tillage, we hypothesized that i) elevated clay contents in arable soil support aggregation already at microaggregate level, leading to ii) increasing organic carbon (SOC) enrichment in smaller SMA size fractions. To test these hypotheses we sampled the topsoil (5-20

$20 \mathrm{~cm}$ ) of Luvisols with a long history of agricultural management at the Scheyern 21 experiment station (Germany) in quintuplicates from each of five subsites with 22 different clay contents (19-34\%). The field-fresh topsoil was fractionated into 23 macroaggregates $(8000-250 \mu \mathrm{m})$, large SMA $(250-20 \mu \mathrm{m})$, and small SMA $(<20 \mu \mathrm{m})$ 24 and the mass distribution was recorded. In addition, the water stable 
macroaggregates $(>250 \mu \mathrm{m})$ were dispersed ultrasonically to study occluded SMA and single building units. Finally, we analyzed the size distribution of the small SMA by laser diffraction analysis. The total mass distribution of free and occluded SMA grouped soils into those with small $(19,22$, and $24 \%)$ and large (32 and $34 \%$ ) clay contents. The finer textured soils exhibited larger portions of occluded SMA, with a gamma size distribution of small SMA peaking at $6 \mu \mathrm{m}$. Yet the occluded small SMA in the finer textured soils showed an additional enrichment of colloids $<1 \mu \mathrm{m}$. The SOC was indeed enriched in finer fractions, but more in the small SMA of the coarse textured sites than in the finer textured ones, whereas the opposite was true for the large SMA. We conclude, therefore, that elevated contents of clay-sized particles promote SMA formation and stabilization, therewith shifting SOC enrichment from small to larger SMA.

\section{Introduction}

Soil microaggregates (SMA) having a size $<250 \mu \mathrm{m}$ are one of the key structures that influence soil properties such as the storage and stabilization of carbon $(C)$, diversity of microbial habitats, diffusion of nutrients and gases, cycling of trace elements, or water retention as recently reviewed by Totsche et al. (2017). Hence, quantifying SMA and their properties has become an essential task in order to predict dynamic changes in soil ecosystems due to management and global change (Six et al., 2004).

Despite the wealth of information on SMA and their role for SOC protection or formation of organo-mineral-associations as building units (Totsche et al., 2017), we still lack information to systematize microaggregate formation across gradients in soil properties. Up to $40 \%$ of organic matter may be stored within SMA (Carter, 1995), 
and the turnover of organic matter is associated with SMA stability (Goebel et al.,

50 2009; Mueller et al., 2012). The stability of microaggregates increases with 51 decreasing diameter of SMA (Golchin et al., 1994; Six et al., 2002; Tisdall, 1996). As a result, SMA are divided into two size fractions, large $(250-20 \mu \mathrm{m})$ and small $(<20$ $\mu \mathrm{m})$ SMA (Oades and Waters, 1991; Tisdall and Oades, 1982; Totsche et al., 2017).

54 Small SMA are believed to be mainly stabilized by short-range van-der-Waals forces and electrostatic binding as reviewed in Totsche et al. (2017). They are stable against a range of forces, and cannot be further disintegrated into smaller building units (Kaiser and Berhe, 2014; Kaiser et al., 2012). This is different for larger aggregate units (Kaiser and Berhe, 2014), which contain small SMA as subunits, held together by roots, hyphae, or extracellular polymeric substances as temporary binding agents (Kleber et al., 2007; Six et al., 2000).

61 It is well established that the amount of clay-sized particles affects the stability and 62 hierarchy of such larger aggregate units (Denef and Six, 2005; Goldberg, 1989; 63 Wagner et al., 2007). Furthermore extensive studies were made about the influence 64 of clay content on the composition and distribution of free and occluded organic matter. These studies showed that clay has an positive effect on the storage of organic carbon in occluded particulate organic matter, which has been linked with 67 increased aggregation in the soils with larger clay content (Kölbl and Kögel-Knabner, 2004). In arable soils, stable organic carbon is mainly associated with fine particle size fractions (Kiem et al., 2002). In turn, organic carbon contributes to the stabilization of microaggregates as well (Kölbl et al., 2005). In soils without tillage and 71 soil management these effects are stronger resulting in an increased soil aggregation 72 and stability as well as improved storage of organic carbon (Ayoubi et al., 2012; 73 Karchegani et al., 2012), which can breakdown during land use change (Schweizer et al., 2017). Furthermore, the stabilization of SOC can also be governed by the 
surface area of oxides influencing the interaction of organic compounds with minerals (Kiem and Kögel-Knabner, 2002). However, detailed studies on the role of clay for the properties of the small SMA $(<20 \mu \mathrm{m})$ as major building units are largely lacking.

We hypothesize that for a given arable land-use system i) elevated clay contents support aggregation not only at macro- but already at microaggregate level, and that ii) stabilization of the smaller size fractions through increased amounts of SOC shifts the overall particle-size distribution to larger equivalent mean weight diameter than at subsites with lower clay contents. In order to test these hypotheses we collected topsoil samples with increasing clay contents from a heterogeneous arable field at Scheyern experiment station, Germany, and investigated the size and mass distribution of small SMA as major building units of their larger counterparts.

\section{Materials and Methods}

\subsection{Soil sampling and sample characteristics}

We selected five adjacent sample sites on the same arable plot (Table A.1; Supplementary Materials) at the research station Scheyern $\left(48^{\circ} 29^{\prime} 36^{\prime \prime} \mathrm{N}, 11^{\circ} 26^{\prime}\right.$ 15 " E) situated in the rural area of the hill slopes north of Munich (Germany) for sampling. Plot selection was facilitated by using gamma spectrometry for sensing textural variations within a heterogeneous field site (Heggemann et al., 2017). The study site was characterized by a mean annual temperature of $7.4^{\circ} \mathrm{C}$ and a mean annual precipitation of $803 \mathrm{~mm}$ (Schröder et al., 2002). The soils were sandy to loamy textured Luvisols, developed on sandy molasse sediments with silty to clayey molasse deposits. All samples were free of carbonates and dominated by illitic clay mineralogy, which did not show systematic differences across the texture gradient $(\mathrm{K}$. 
U. Totsche, personal communication, 2018). Other clay minerals detected were Fe-

100 chlorite, kaolinite and smectite, the latter however only in samples with 12 and $18.5 \%$ 101 clay, the other samples contained vermiculite instead (K. U Totsche, personal 102 communication).

103 Overall 25 samples were used for analysis from each of five sampling sites with five 104 replicates each, taken in a radial sampling scheme (1 $\mathrm{m}$ around each subsite; Wilding 105 (1985)). Samples were taken after removal of the upper Ap layer prone to crust 106 formation (first $4-5 \mathrm{~cm}$ ) with a large core cutter (diameter: $16 \mathrm{~cm}$, length: $15 \mathrm{~cm}$, 107 volume: $\sim 3000 \mathrm{~cm}^{2}$ ). Clay contents were determined based on texture analysis using $108 \mathrm{H}_{2} \mathrm{O}_{2}$ oxidation. About $10 \mathrm{~g}$ of each sample was treated with an excess of $\mathrm{H}_{2} \mathrm{O}_{2}$ 109 (30\%) until no further oxidation could be observed. The oxidized samples were put 110 into an oven at $60{ }^{\circ} \mathrm{C}$ with additional $500 \mathrm{~mL} \mathrm{H}_{2} \mathrm{O}$ for 12 hours to remove excess $111 \mathrm{H}_{2} \mathrm{O}_{2}$. Then, the samples were sieved $<63 \mu \mathrm{m}$, freeze-dried and $3 \mathrm{~g}$ were mixed with $11280 \mathrm{~mL} 0.0125 \mathrm{M} \mathrm{Na}_{4} \mathrm{P}_{2} \mathrm{O}_{7}$. The clay content was determined by X-ray attenuation in a 113 Sedigraph III Plus (Micromeritics, Georgia, USA). The clay contents were 19, 22, 24, 11432 , and 34\%, respectively. Additionally $100 \mathrm{~cm}^{3}$ cores were sampled for field 115 moisture and bulk density determination. The fresh soil samples were gently sieved $116<8 \mathrm{~mm}$ and stored at $4{ }^{\circ} \mathrm{C}$. The $\mathrm{Fe}, \mathrm{Al}$, and $\mathrm{Mn}$ phases $\left(\mathrm{Fe}_{\mathrm{D}}, \mathrm{Al} \mathrm{D}, \mathrm{Mn}_{\mathrm{D}}\right)$ were extracted 117 using dithionite-citrate-bicarbonate (DCB) according to Mehra and Jackson (1958), 118 serving as a measure for the abundance of pedogenic oxides. The extracts were 119 analyzed with inductively coupled plasma optical emission spectroscopy (ICP-OES) 120 Vista-Pro (Varian, California, USA). The total C contents in each aggregate fraction 121 were determined using elemental analysis (Vario MICRO cube, Elementar 122 Analysesysteme GmbH, Langenselbold, Germany), according to ISO 10694 (1995). 
2.2 Wet fractionation and density fractionation

125 The fractionation was conducted on field-moist soil in triplicates, using a combination 126 of wet sieving and pressure filtration (Fig. 1). In order to avoid re-aggregation, the 127 samples were kept submerged in deionized water during the whole process of 128 fractionation until they were shock frozen in liquid nitrogen and lyophilized. In short, $12950 \mathrm{~g}$ of $8 \mathrm{~mm}$ field fresh sieved samples were placed on a glass fiber filter being on 130 the top of a sieve tower and pre-wetted for five minutes. The sample was then sieved 131 in a sieve-tower using 6 sieves having a mesh size between 2800 to $20 \mu \mathrm{m}$ (Fig. 1) 132 under constant shaking $\left(30 \cup \mathrm{min}^{-1}\right)$ for 10 minutes. Collected fractions were 133 categorized into free and occluded SMA. Free SMA (250-53, 53-20, and 20-0.22 $\mu \mathrm{m})$ 134 were collected without further treatment. In order to isolate occluded SMA, remnants 135 of wet sieving being $>250 \mu \mathrm{m}$ were merged, suspended in $\mathrm{H}_{2} \mathrm{O}$ and subjected to an 136 ultrasonic treatment using $60 \mathrm{~J} \mathrm{~mL}^{-1}$ (Branson Ultrasonics corp., Connecticut, USA) 137 as recommended by Amelung and Zech (1999). After ultrasonic treatment the 138 suspension was wet sieved using the sieve tower as described above starting with 139 the $2800 \mu \mathrm{m}$ sieve and obtained size fractions being $>250,250-53,53-20$, and $<20$ $140 \mu \mathrm{m}$ using the sieving tower described by Kösters et al. (2013).

141 Wet sieving resulted in approximately $50 \mathrm{~L}$ suspensions each containing $<20 \mu \mathrm{m}$ 142 fractions of free and occluded SMA. The collection of small SMA was performed 143 through pressure filtration. Homogenized aliquots were pressure filtered (Pressure 144 filter Holder Type 16274, Sartorius, Göttingen, Germany) with 2-3 bar $\mathrm{N}_{2}$ through a $1450.22 \mu \mathrm{m}$ PVDF filter (Membrane filter PVDF hydrophilic, 1201322, Berrytec GmbH, 146 Oberbayern, Germany). After filtration the remnants were removed from the 147 membrane filter with $\mathrm{H}_{2} \mathrm{O}$, the resulting suspension was shock frosted in liquid 148 nitrogen and freeze-dried. The collected $<0.22 \mu \mathrm{m}$ fraction was considered as 
149

150

151

152

153

154

155

156

157 158

nanoparticle fraction. The process of fractionation resulted in an average total mass recovery of $97 \%$.

Since the collected large SMA and macroaggregates still contained primary mineral particles, a density fractionation with sodium metatungstate was performed with pooled field replicates according to Virto et al. (2008). With this method, primary sand and silt particles with a density of $>2.5 \mathrm{~g} \mathrm{~cm}^{-3}$ were removed from the affected size fractions. Particulate organic matter (POM) with a density of $1.6-1.8 \mathrm{~g} \mathrm{~cm}^{-3}$ was not removed in an additional step since the mass contribution of the POM fractions was limited to a minor proportion (Kölbl and Kögel-Knabner, 2004).

\subsection{Particle size distribution}

The size distribution of small SMA $(<20 \mu \mathrm{m})$ was measured with a laser particle-size analyzer (LA-950, Horiba, Kyōto, Japan). Before each measurement the sample was suspended in water and ultrasonicated $\left(13 \mathrm{~J} \mathrm{~mL}^{-1}\right)$ using the internal ultrasonic finger of the instrument. During the measurement the SMA were kept in suspension through stirring. The scattered light data was transformed into a volume based size distribution by a software algorithm using the mie-theory provided by the manufacturers' software.

\subsection{Statistical tests}

Calculation of Pearsons correlation coefficients between clay content and measured elements was performed with Excel (Microsoft Excel 2010, Microsoft corporation, Washington, USA). Statistical analysis was performed with Origin (OriginPro 2017, Originlab, Massachusetts, USA). The Shapiro Wilk test was used for testing the 
173 normal distribution. With the one-way ANOVA the statistical significance was tested

174 at a significance level of $\alpha=0.05$ and in a post-hoc test the means were compared 175 with Tukey's method. The tests were applied for the SOC and mass percentage data, 176 each pooled into soils with small (19-24\%) and large (33-34\%) clay content. Overall 177 four levels of significance were defined and indicated by asterisks (not significant, $178 \mathrm{p}>0.05$, no symbol; significant, $\mathrm{p} \leq 0.05,{ }^{*}$; very significant, $\mathrm{p} \leq 0.01$, **; highly 179 significant, $p \leq 0.001,{ }^{* * *}$; extremely significant, $\left.p \leq 0.0001,{ }^{* * *}\right)$.

\section{Results}

181 Generally, the subsampling of the sites was successful in yielding samples with 182 different texture: as clay content increased from $19-34 \%$, mass proportions of sand 183 decreased respectively (Fig. 2). When $\mathrm{NaOCl}$ was used instead of $\mathrm{H}_{2} \mathrm{O}_{2}$, the 184 respective clay contents were slightly lower, but changed in similar direction (Table 185 A.2; Supplementary Materials). Intriguingly, the $\mathrm{Fe}_{\mathrm{D}}$ content did not show significant 186 differences along this transect, being in average $8.3 \mathrm{~g} \mathrm{~kg}^{-1}$ in soils with $19-24 \%$ clay, 187 and $8.5 \mathrm{~g} \mathrm{~kg}^{-1}$ in soils with larger clay content (32-34\%), respectively (Table A.2; 188 Supplementary Materials). In turn, correlation coefficients of 0.83 and 0.87 indicate 189 that the concentrations of $A I_{D}$ and $M n_{D}$ increased with clay content (Table A.2; 190 Supplementary Materials). With density fractionation the mass of primary mineral 191 particles with a density of $>2.5 \mathrm{~g} \mathrm{~cm}^{-3}$ was evaluated. For the $8000-250 \mu \mathrm{m}$ fractions, 192 the average mass percentage of primary mineral particles reached $94 \%$ and $96 \%$ soil 193 mass, being slightly larger in soils with larger clay content compared to soils with 194 smaller clay content (Table A.2; supplementary materials). For all 250-20 $\mu \mathrm{m}$ 195 fractions, i.e., the large SMA fractions, the mass percentage of primary mineral 196 particles averaged $80 \%$ without noticeable differences between subsites of different 197 clay contents. Intriguingly, the amount of primary particles in "free" fractions was 
198 lower $(75 \%)$ than in the occluded fractions (84\%; data not shown). The small SMA

199 fraction was not corrected for primary particle contents.

\section{$2013.1 \quad$ SMA mass distribution}

202 Unlike the textural gradient, the evaluation of isolated fractions indicated that the 203 mass distribution of soil aggregates was not linearly related to the amount of clay204 sized particles, but rather grouped into soils having small and large clay content, 205 respectively (Fig. 3a). Samples with large clay content showed large amounts of 206 occluded small SMA, while samples with small clay contents showed less occluded 207 small SMA and higher content of free SMA (Fig. 3b). The main differences between 208 samples with small and large clay content were thus the amount of occluded small 209 SMA, the proportion of which was significantly larger in soils with $\geq 32 \%$ clay (Fig. 4). 210 The mass-proportion of free small SMA was also affected by clay content and 211 significantly larger in soils with smaller clay contents.

$213 \quad 3.2 \quad$ Size distribution of the small SMA

214 The volume weighted size distribution of small SMA followed mainly the gamma 215 distribution (Fig. A.1; Supplementary Materials). More than $90 \%$ of the measured 216 fraction was $\leq 10 \mu \mathrm{m}$ (Fig. 5). The most abundant size class of small SMA was found 217 in the range of 5 to $7 \mu \mathrm{m}$ (Fig. 5a). Intriguingly, this size distribution was similar for 218 free and occluded small SMA, which can be clearly seen by comparison of the 219 cumulative percentages (Fig. 5b). In addition, however, soils with larger clay content $220(\geq 32 \%)$ showed an additional abundance of particles $\leq 1 \mu \mathrm{m}$ within the occluded small

221 SMA (Fig. 5c, d), pointing to a potential role of colloids in SMA occlusion. To better 
222 understand the underlying mechanisms, we assessed the concentrations of SOC 223 inside the different SMA fractions.

\subsection{SOC content of different SMA fractions}

226 The SOC contents did not strongly correlate with the gradient of clay content but 227 showed some differences between small (19-24\%) and large (32-34\%) clay content. 228 Apparently, the relationship between SOC-enrichment in clay and clay-content was 229 not linear (see also Christensen (1992)). Compared to the SMA fraction with small 230 clay content the total SOC concentration of SMA from soils with larger clay content 231 had increased significantly in the free and decreased in occluded SMA (Fig. 6a). 232 There were no significant differences in SOC contents between the free and 233 occluded SMA from soils with small clay content. However, the relationship of the 234 SOC content of the SMA to the clay content was not a linear, i.e., the data grouped 235 similarly as did the mass distribution of SMA, we keep the comparison of SOC within 236 SMA of sites with low ( $\leq 24 \%$ clay) and large clay content $(\geq 32 \%)$, respectively.

237 Overall in the soil sequence, larger SOC concentrations were found in the small SMA 238 fraction than in the large SMA. It contained larger amounts of SOC in occluded SMA 239 than in the free ones, and larger amounts of SOC in the coarser than in the finer 240 textured soils (Fig. 6b). In contrast to the observations from small SMA, the large 241 SMA fractions had significantly larger SOC concentrations in the free than in the 242 occluded SMA, with now also larger SOC contents in the samples with larger clay 243 contents than in the coarser textured ones (Fig. 6c). Hence, the distribution of SOC 244 into occluded and free aggregates as well as among the differently textured soils just 245 behaved opposite in the small SMA relative to the large SMA. 


\section{Discussion}

247 The applied fractionation scheme enabled us deeper insights into the dynamic 248 aggregation processes at different scales ranging from macroaggregates to small 249 SMA. The disruption energy of $60 \mathrm{~J} \mathrm{~mL}^{-1}$ has been considered as suitable for 250 evaluating the SMA size distribution and associated organic matter (Kölbl et al., 251 2005) preserving largely their natural state (Amelung and Zech, 1999). Differentiation 252 between occluded and free aggregates supported our first hypotheses that elevated 253 clay contents support aggregation not only at macro- but already at microaggregate 254 level. Specifically, elevated clay contents promoted the formation of occluded SMA 255 (Fig. 4), likely by higher aggregate stability through interactions with more abundant 256 colloids $<1 \mu \mathrm{m}$ (Fig. 5). In this regard, our data are in support of the concept of 257 aggregate hierarchy (Oades and Waters, 1991), in that macroaggregates are built 258 from microaggregates which can be formed from smaller building units. Here we 259 show a novel size distribution measurement of the smaller building units ( 0.1 to 1 $260 \mu \mathrm{m})$, which was significant higher at sites with elevated clay content. The occluded 261 and free small SMA reveals a gamma like size distribution (Fig. A.1; Supplementary 262 Materials) peaking at 4-6 $\mu \mathrm{m}$ (Fig. 5). The gamma distribution model showed the best 263 fit in comparison to other models which is in agreement with the work of Yang et al. 264 (2012).

265 The similar size distribution of free and occluded particles in soils with low clay 266 content (Fig. 5a) indicated that there is no preferential accumulation of specific sized 267 free small SMA during aggregation. The evaluation of the total masses of soil 268 aggregate fractions showed that the macroaggregate/SMA ratios became narrower 269 when moving to subsites with larger clay content. This agrees with Yu et al. (2015), 270 who found similar changes in macroaggregate/SMA ratios as a function of silt and 271 clay content. In soils with large clay content the abundance of occluded small SMA 
272 increased, which indicates larger amounts of water stable aggregates and thus an

273 essential role of the clay-sized fraction not only for the formation but also for the 274 stability of SMA.

275 It has been suggested that a minimum clay content of $15 \%$ is required for the abiotic 276 formation of aggregates (Horn, 1990; Oades, 1993). The percentage of the analyzed 277 low clay content soils (19-24\%) was above this minimum value. An additional factor 278 contributing to more occluded SMA in soils with large clay content could be the 279 significantly larger concentrations of Al- and Mn-bearing phases (Appendix Table 280 A.2); at least for aluminum oxides it is known that they promote the stabilization of 281 clay minerals and organic matter on mineral surfaces (Goldberg, 1989; Kögel282 Knabner et al., 2008).

283 Another essential factor promoting SMA formation is organic matter. Our results 284 showed that especially small SMA were rich in SOC (Fig 6b, c), which confirms 285 previous studies showing that organic carbon mainly accumulates in the smallest 286 fractions with the largest specific surface area (Kahle et al., 2002; Kennedy et al., 287 2002). In addition, the SOC concentrations were higher in occluded small SMA than 288 in the free ones (Fig. 6b), confirming previous findings that only clayey soils supplied 289 with organic matter were able to aggregate and that there is a strong correlation 290 between SOC accrual and aggregate stability (Al-Kaisi et al., 2014; Imhoff et al., 291 2002; Wagner et al., 2007). In turn, more stable aggregates also protect SOC better 292 from degradation as aggregates that disintegrate. Through occlusion, for instance, $293 \mathrm{SOC}$ is better protected against microbial decomposition in the $<20 \mu \mathrm{m}$ fraction than 294 in larger SMA (Hassink, 1997). Physical stabilization affects the turnover of labile 295 molecules like carbohydrates and proteins (Krull et al., 2003) that can act as gluing 296 agents for aggregates. Previous studies showed that this SOC protection works in 
297 addition to chemical and biochemical stabilization (Six et al., 2002) due to the 298 preservation of polysaccharides and phenolic C in the clay fraction (De Nobili et al., 299 2008; Schöning et al., 2005). The microbial cycling of SOC nearby mineral surfaces 300 fosters the accrual of carbohydrate and other microbial residues (Amelung et al., 301 1997; Zhang et al., 1999), which might act as glue within microaggregate cores (Ladd 302 et al., 1993; Lynch and Bragg, 1985; Rodionov et al., 2001). As a result, soil organic 303 matter composition may vary with aggregate size (Golchin et al., 1994; Yu et al., 304 2015). In this regard, a higher SOC concentration in occluded small SMA relative to 305 the free SMA (Fig. 6b) might be explained by an enrichment of microbial-altered SOC 306 (Bingham and Cotrufo, 2016; Cotrufo et al., 2013; Rodionov et al., 2001), whereas 307 fungal hyphae and fine root debris might be part of free SOC, enriched within the free 308 large SMA fraction (Fig. 6c). According to Amelung et al. (2002), SOC accumulation 309 in microaggregates may well happen at the outer surface, i.e., it does not necessarily 310 have to result in an additional occlusion process. Nevertheless, this different direction 311 of SOC enrichment hardly altered the size distribution of SMA with increasing clay 312 content (Fig. 5).

\section{Conclusion}

314 Results indicated that the abundance of clay-sized particles as building unit is a 315 superior requirement for aggregate formation and stability. Elevated clay contents 316 promote the formation and stability of SMA with different size, resulting in larger

317 concentrations of occluded SMA than of free ones as clay contents rose. Notably, 318 SOC enrichment followed the opposite direction, i.e., the additional clay mostly 319 trapped SOC in free, large SMAs. We attribute this to an interaction loop: the 320 preferred formation of occluded aggregates with elevated clay contents leads to 
321 lower amounts of "free" particles, which therewith concentrate the remaining SOC at 322 their surface.

\section{Acknowledgements}

324 We acknowledge A. Lindecke for performing the $\mathrm{C} / \mathrm{N}$ analysis. Furthermore we want 325 to thank Dr. Daniel Emil Mack and Andrea Hilgers for the support of the particle size 326 analysis, and I. Kögel-Knaber for helpful discussions. This work is associated to the 327 MAD Soil project, which was funded by the DFG (Deutsche 328 Forschungsgemeinschaft, Research Unit 2171 


\section{References}

331 Al-Kaisi, M.M., Douelle, A., Kwaw-Mensah, D., 2014. Soil microaggregate and macroaggregate decay over time and soil carbon change as influenced by different tillage systems. Journal of Soil and Water Conservation 69, 574-580. Amelung, W., Kaiser, K., Kammerer, G., Sauer, G., 2002. Organic carbon at soil particle surfaces-evidence from $\mathrm{x}$-ray photoelectron spectroscopy and surface abrasion. Soil Science Society of America Journal 66, 1526-1530. Amelung, W., Zech, W., 1999. Minimisation of organic matter disruption during particle-size fractionation of grassland epipedons. Geoderma 92, 73-85. Amelung, W., Zech, W., Flach, K.W., 1997. Climatic Effects on Soil Organic Matter Composition in the Great Plains. Soil Science Society of America Journal 61, 115123. Ayoubi, S., Mokhtari Karchegani, P., Mosaddeghi, M.R., Honarjoo, N., 2012. Soil aggregation and organic carbon as affected by topography and land use change in western Iran. Soil and Tillage Research 121, 18-26.

Bingham, A.H., Cotrufo, M.F., 2016. Organic nitrogen storage in mineral soil:

Implications for policy and management. Science of The Total Environment 551, 116126.

Carter, M.R., 1995. Analysis of Soil Organic Matter Storage in Agroecosystems, In: Carter, M.R., Stewart, B.A. (Eds.), Structure and Organic Matter Storage in Agricultural Soils. Taylor \& Francis, Boca Raton, FL, pp. 3-11. Christensen, B.T., 1992. Physical fractionation of soil and organic matter in primary particle size and density separates, In: Stewart, B.A. (Ed.), Advances in Soil Science. Springer New York, pp. 1-90.

Cotrufo, M.F., Wallenstein, M.D., Boot, C.M., Denef, K., Paul, E., 2013. The Microbial Efficiency-Matrix Stabilization (MEMS) framework integrates plant litter decomposition with soil organic matter stabilization: do labile plant inputs form stable soil organic matter? Global Change Biology 19, 988-995.

De Nobili, M., Contin, M., Mahieu, N., Randall, E.W., Brookes, P.C., 2008. Assessment of chemical and biochemical stabilization of organic $C$ in soils from the long-term experiments at Rothamsted (UK). Waste Management 28, 723-733. Denef, K., Six, J., 2005. Clay mineralogy determines the importance of biological versus abiotic processes for macroaggregate formation and stabilization. European Journal of Soil Science 56, 469-479.

Goebel, M.-O., Woche, S.K., Bachmann, J., 2009. Do soil aggregates really protect encapsulated organic matter against microbial decomposition? Biologia 64, 443-448. Golchin, A., Oades, J., Skjemstad, J., Clarke, P., 1994. Soil structure and carbon cycling. Soil Research 32, 1043-1068.

Goldberg, S., 1989. Interaction of aluminum and iron oxides and clay minerals and their effect on soil physical properties: A review. Communications in Soil Science and Plant Analysis 20, 1181-1207.

Hassink, J., 1997. The capacity of soils to preserve organic $\mathrm{C}$ and $\mathrm{N}$ by their association with clay and silt particles. Plant and Soil 191, 77-87. Heggemann, T., Welp, G., Amelung, W., Angst, G., Franz, S.O., Koszinski, S., Schmidt, K., Pätzold, S., 2017. Proximal gamma-ray spectrometry for siteindependent in situ prediction of soil texture on ten heterogeneous fields in Germany using support vector machines. Soil and Tillage Research 168, 99-109. 
Horn, R., 1990. Aggregate characterization as compared to soil bulk properties. Soil and Tillage Research 17, 265-289. Imhoff, S., da Silva, A.P., Dexter, A., 2002. Factors Contributing to the Tensile 1661.

Kahle, M., Kleber, M., Jahn, R., 2002. Carbon storage in loess derived surface soils from Central Germany: Influence of mineral phase variables. Journal of Plant Nutrition and Soil Science 165, 141-149.

Kaiser, M., Berhe, A.A., 2014. How does sonication affect the mineral and organic constituents of soil aggregates? -A review. Journal of Plant Nutrition and Soil Science 177, 479-495.

Kaiser, M., Berhe, A.A., Sommer, M., Kleber, M., 2012. Application of ultrasound to disperse soil aggregates of high mechanical stability. Journal of Plant Nutrition and Soil Science 175, 521-526.

Karchegani, P.M., Ayoubi, S., Mosaddeghi, M.R., Honarjoo, N., 2012. Soil organic carbon pools in particle-size fractions as affected by slope gradient and land use change in hilly regions, western Iran. Journal of Mountain Science 9, 87-95.

Kennedy, M.J., Pevear, D.R., Hill, R.J., 2002. Mineral Surface Control of Organic Carbon in Black Shale. Science 295, 657-660.

Kiem, R., Knicker, H., Kögel-Knabner, I., 2002. Refractory organic carbon in particlesize fractions of arable soils I: distribution of refractory carbon between the size fractions. Organic Geochemistry 33, 1683-1697.

Kiem, R., Kögel-Knabner, I., 2002. Refractory organic carbon in particle-size fractions of arable soils II: organic carbon in relation to mineral surface area and iron oxides in fractions $<6 \mu \mathrm{m}$. Organic Geochemistry 33, 1699-1713.

Kleber, M., Sollins, P., Sutton, R., 2007. A conceptual model of organo-mineral interactions in soils: self-assembly of organic molecular fragments into zonal structures on mineral surfaces. Biogeochemistry 85, 9-24.

Kögel-Knabner, I., Guggenberger, G., Kleber, M., Kandeler, E., Kalbitz, K., Scheu, S., Eusterhues, K., Leinweber, P., 2008. Organo-mineral associations in temperate soils: Integrating biology, mineralogy, and organic matter chemistry. Journal of Plant Nutrition and Soil Science 171, 61-82.

Kölbl, A., Kögel-Knabner, I., 2004. Content and composition of free and occluded particulate organic matter in a differently textured arable Cambisol as revealed by solid-state 13C NMR spectroscopy. Journal of Plant Nutrition and Soil Science 167, 45-53.

Kölbl, A., Leifeld, J., Kögel-Knabner, I., 2005. A comparison of two methods for the isolation of free and occluded particulate organic matter. Journal of Plant Nutrition and Soil Science 168, 660-667.

Kösters, R., Preger, A.C., Du Preez, C.C., Amelung, W., 2013. Re-aggregation dynamics of degraded cropland soils with prolonged secondary pasture management in the South African Highveld. Geoderma 192, 173-181.

Krull, E.S., Baldock, J.A., Skjemstad, J.O., 2003. Importance of mechanisms and processes of the stabilisation of soil organic matter for modelling carbon turnover. Functional plant biology 30, 207-222.

Ladd, J.N., Foster, R.C., Skjemstad, J.O., 1993. Soil structure: carbon and nitrogen metabolism. Geoderma 56, 401-434. Lynch, J.M., Bragg, E., 1985. Microorganisms and Soil Aggregate Stability, In: Stewart, B.A. (Ed.), Advances in Soil Science. Springer New York, New York, NY, pp. 133-171. 
427 Mehra, O.P., Jackson, M.L., 1958. Iron Oxide Removal from Soils and Clays by a 428 Dithionite-Citrate System Buffered with Sodium Bicarbonate. Clays and Clay Minerals 429 7, 317-327.

430 Mueller, C.W., Schlund, S., Prietzel, J., Kögel-Knabner, I., Gutsch, M., 2012. Soil

431 Aggregate Destruction by Ultrasonication Increases Soil Organic Matter

432 Mineralization and Mobility. Soil Science Society of America Journal 76, 1634-1643.

433 Oades, J., Waters, A., 1991. Aggregate hierarchy in soils. Soil Research 29, 815-

434828.

435 Oades, J.M., 1993. The role of biology in the formation, stabilization and degradation 436 of soil structure. Geoderma 56, 377-400.

437 Rodionov, A., Amelung, W., Urusevskaja, I., Zech, W., 2001. Origin of the enriched 438 labile fraction (ELF) in Russian Chernozems with different site history. Geoderma 439 102, 299-315.

440 Schöning, I., Morgenroth, G., Kögel-Knabner, I., 2005. O/N-alkyl and alkyl C are 441 stabilised in fine particle size fractions of forest soils. Biogeochemistry 73, 475-497. Schröder, P., Huber, B., Olazábal, U., Kämmerer, A., Munch, J.C., 2002. Land use and sustainability: FAM Research Network on Agroecosystems. Geoderma 105, 155166.

Schweizer, S.A., Fischer, H., Häring, V., Stahr, K., 2017. Soil structure breakdown following land use change from forest to maize in Northwest Vietnam. Soil and Tillage Research 166, 10-17.

Six, J., Bossuyt, H., Degryze, S., Denef, K., 2004. A history of research on the link between (micro)aggregates, soil biota, and soil organic matter dynamics. Soil and Tillage Research 79, 7-31.

Six, J., Conant, R.T., Paul, E.A., Paustian, K., 2002. Stabilization mechanisms of soil organic matter: Implications for C-saturation of soils. Plant and Soil 241, 155-176.

Six, J., Elliott, E.T., Paustian, K., 2000. Soil macroaggregate turnover and microaggregate formation: a mechanism for $\mathrm{C}$ sequestration under no-tillage agriculture. Soil Biology and Biochemistry 32, 2099-2103.

Tisdall, J.M., 1996. Formation of soil aggregates and accumulation of soil organic matter, In: Carter, M.R., Stewart, B.A. (Eds.), Structure and organic matter storage in agricultural soils. Taylor \& Francis, Boca Raton, FL, pp. 57-87.

Tisdall, J.M., Oades, J.M., 1982. Organic matter and water-stable aggregates in soils. Journal of Soil Science 33, 141-163.

Totsche, K.U., Amelung, W., Gerzabek, M.H., Guggenberger, G., Klumpp, E., Knief, C., Lehndorff, E., Mikutta, R., Peth, S., Prechtel, A., Ray, N., Kögel-Knabner, I., 2017. Microaggregates in soils. Journal of Plant Nutrition and Soil Science, n/a-n/a. Virto, I., Barré, P., Chenu, C., 2008. Microaggregation and organic matter storage at the silt-size scale. Geoderma 146, 326-335.

Wagner, S., Cattle, S.R., Scholten, T., 2007. Soil-aggregate formation as influenced by clay content and organic-matter amendment. Journal of Plant Nutrition and Soil Science 170, 173-180.

Wilding, L.G., 1985. Spatial variability: Its documentation, accommodation and implication to soil survey, In: Nielsen, D.R., J., B. (Eds.), Soil spatial variability: proceedings of a workshop of the ISSS and the SSSA, Las Vegas, USA, Wageningen, Netherlands, pp. 166-187.

Yang, X., Lee, J., Barker, D.E., Wang, X., Zhang, Y., 2012. Comparison of six particle size distribution models on the goodness-of-fit to particulate matter sampled from animal buildings. Journal of the Air \& Waste Management Association 62, 725-735. Yu, H., Ding, W., Chen, Z., Zhang, H., Luo, J., Bolan, N., 2015. Accumulation of organic C components in soil and aggregates. Scientific Reports 5, 13804. 


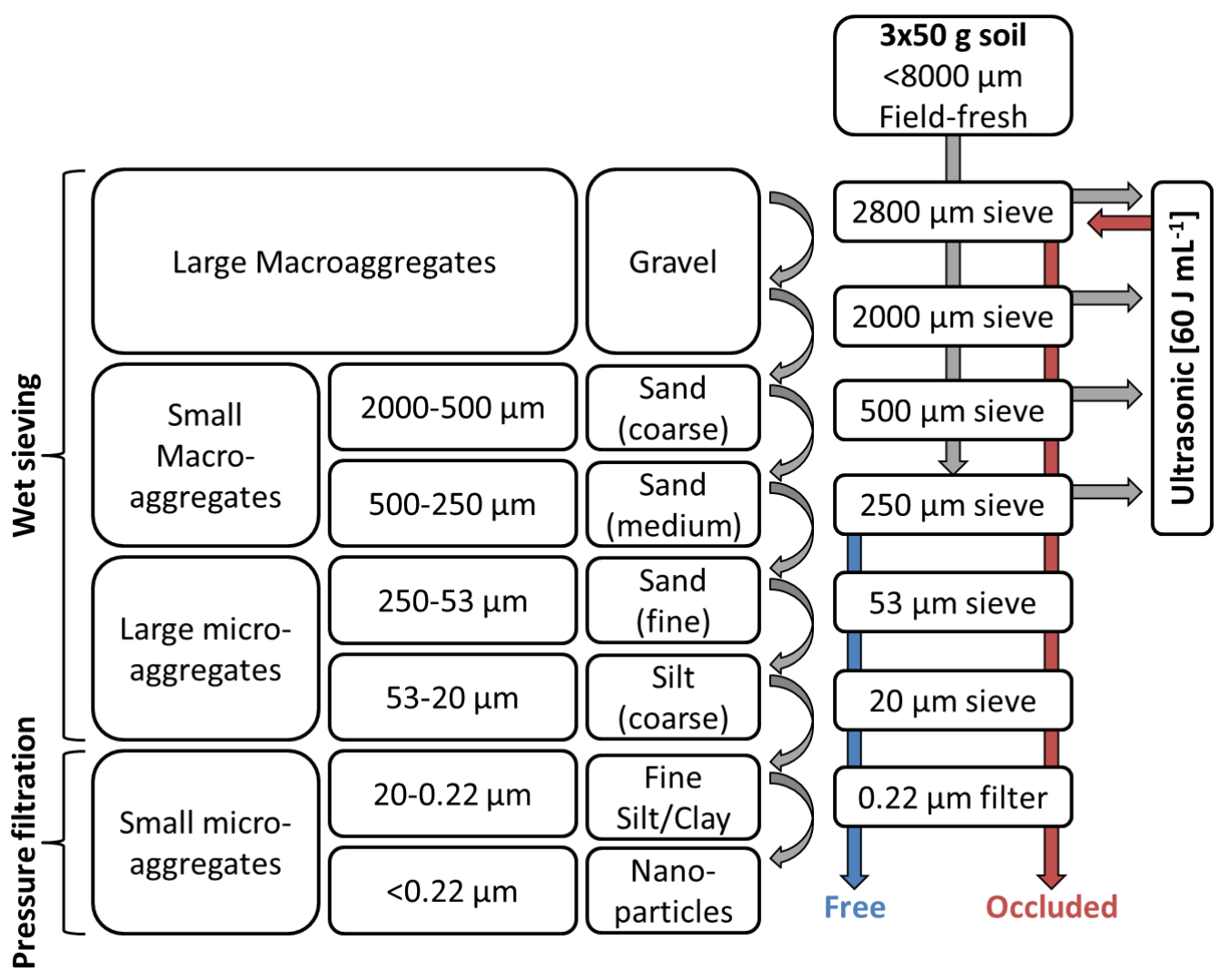

Fig. 1. Overview about the fractionation process using wet sieving and pressure filtration. According to the different size fractions the samples were divided into macroaggregates, large, and small SMA. Mechanical disaggregation via ultrasonication allowed a differentiation between occluded (ultrasonic treatment, red arrow) and free (no treatment, blue arrow) SMA. 


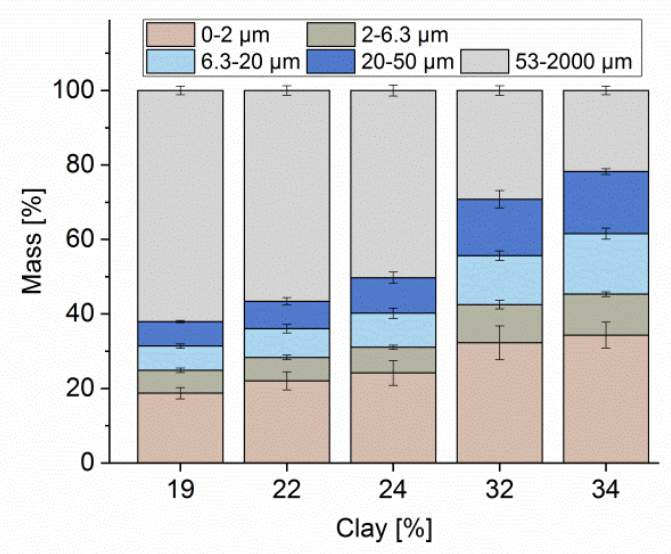

Fig. 2. Texture of $\mathrm{H}_{2} \mathrm{O}_{2}$ oxidized soil samples obtained from the toposequence at an agricultural site.

485
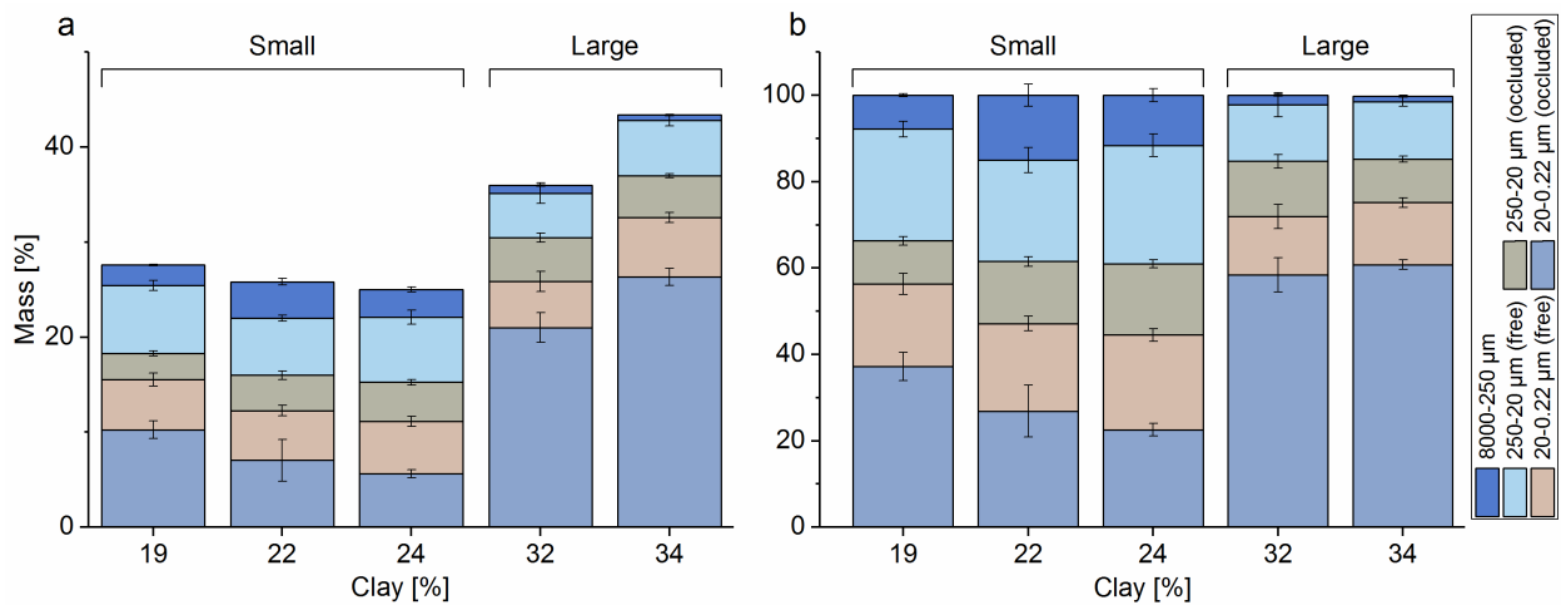

Fig. 3. Mass percentage of macroaggregates and SMA in bulk soil (a) and within SMA (b) of soils with different clay content (small and large). 


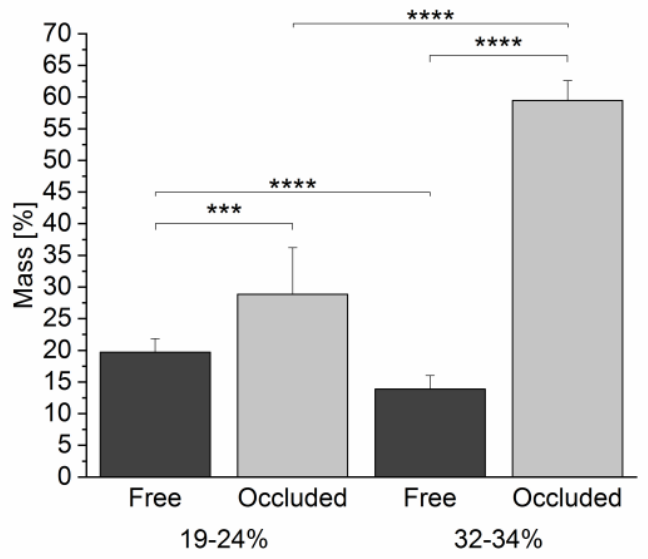

Fig. 4. Mass percentage of free and occluded small SMA; significant differences are indicated with asterisks.
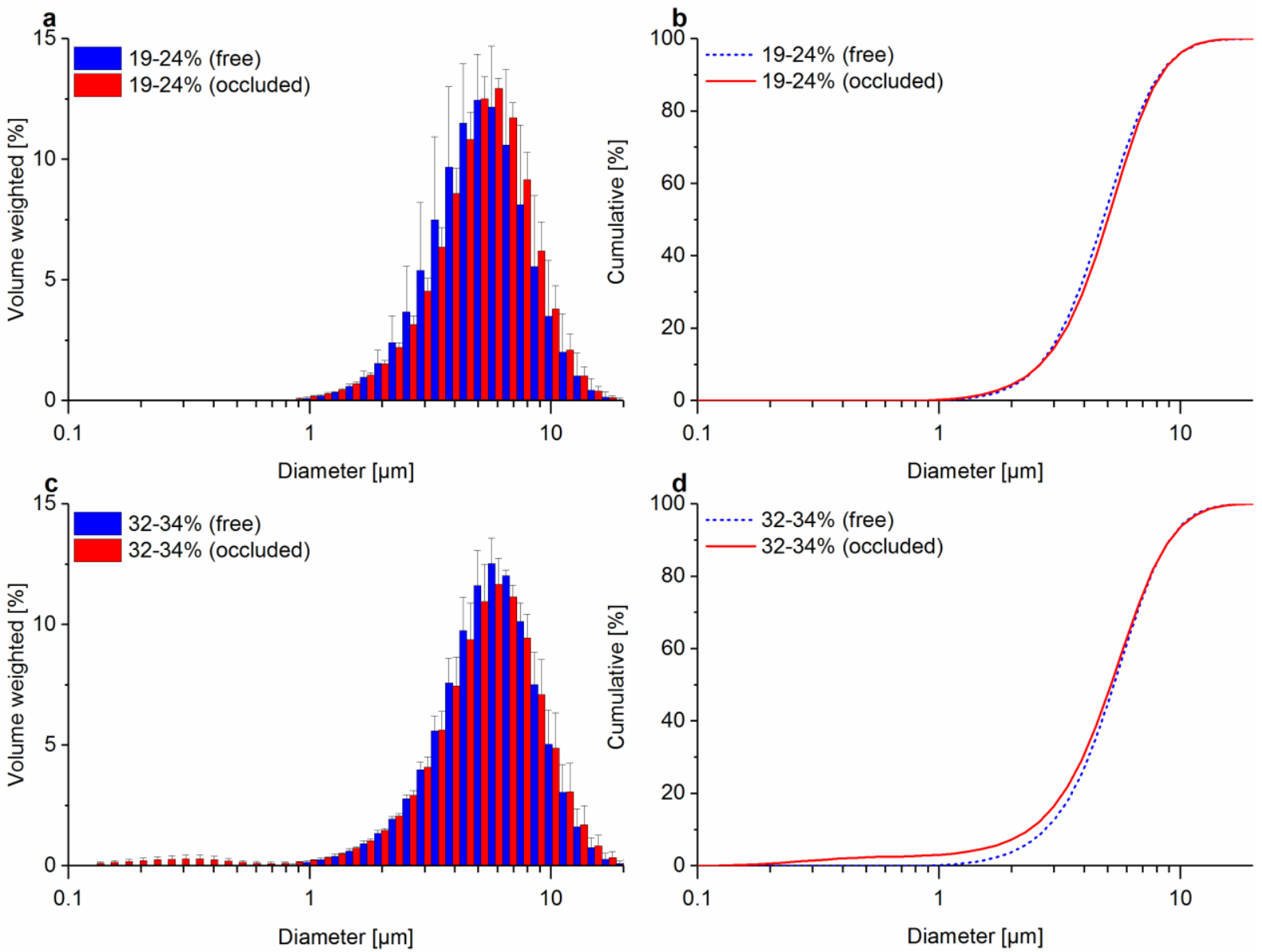

Fig. 5. Volume based size distribution (a, $\mathbf{c})$ and cumulative percentage (b, $\mathbf{d})$ of free (blue/dotted) and occluded (red/straight) SMA for soils with small (a, b) and large (b, c) clay content. 

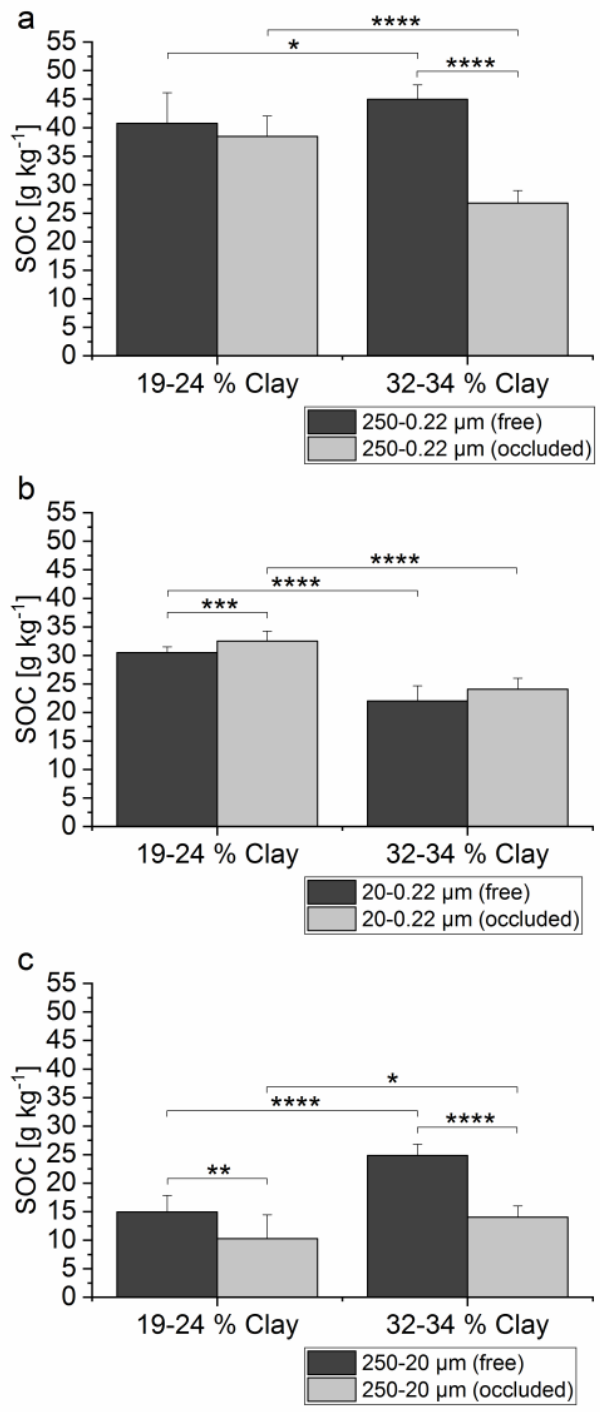

Fig. 6. SOC content in dependence of soil clay content for all SMA (a) and their corresponding fractions including small (b) and large (c) SMA. The proportion of the free form is indicated in black and the occluded form in grey. Significant differences are indicated with asterisks. 